\title{
Pruebas rápidas para detección de anticuerpos para el diagnóstico de COVID19: consideraciones para su uso en el contexto colombiano
}

\section{Ángel González}

La pandemia causada por el coronavirus SARS-CoV-2 (por sus siglas en inglés Severe Acute Respiratory Syndrome Coronavirus 2), el cual causa la enfermedad conocida como COVID-19, viene incrementando de manera significativa en nuestro país, a pesar de la estrategia del aislamiento o confinamiento preventivo obligatorio decretado por el Gobierno Nacional.

Actualmente el diagnóstico de esta enfermedad se basa en la detección de ácidos nucleicos mediante la técnica de PCR en tiempo real (RT-PCR), considerada la prueba de oro o "Gold Standard". La implementación de esta metodología en nuestro país presenta algunas limitaciones, entre las que se encuentran: i) tiempos de respuesta largos que pueden tomar más de 4 o 5 días para la emisión de los resultados; (ii) requieren laboratorios certificados, equipos costosos y personal capacitado para la implementación de la misma ${ }^{1}$ y (iii) escasez de reactivos e insumos en el medio que deben ser importados debido a la falta de capacidad de producción en el país. Adicionalmente, los resultados dependen del tipo de muestra utilizada, siendo más sensible para muestras obtenidas por procedimientos invasivos como el aspirado traqueal y el lavado/cepillado bronquial, seguido por muestras obtenidas por métodos no invasivos como los hisopados orofaríngeos y nasofaríngeos. ${ }^{1-3}$ Dadas las características de estas pruebas moleculares, su implementación es viable solo en laboratorios de referencia en las ciudades donde la infraestructura y equipamientos están disponibles; en consecuencia, el diagnóstico en ciudades intermedias o municipios alejados se convierte en un gran reto, dado que las muestras deben ser remitidas siguiendo algunas condiciones especiales para el transporte que eviten la degradación del RNA, el cual es muy lábil a los cambios de temperatura. A pesar de estas limitaciones, las pruebas basadas en la detección del RNA viral son la mejor alternativa disponible para el diagnóstico confirmatorio de la enfermedad en la fase aguda.

Por otro lado, se han desarrollado pruebas rápidas basadas en la detección de anticuerpos, fáciles de usar en campo, sensibles, específicas y útiles para estudiar la exposición a SARS-CoV-2. ${ }^{2}$ Varios estudios han explorado el uso de las pruebas serológicas mediante la detección de anticuerpos tipo $\operatorname{IgM}$, IgA, IgG o anticuerpos totales en suero, plasma o sangre total. No obstante, es importante anotar que el desarrollo o producción de anticuerpos en respuesta a una infección depende del hospedero; en el caso de COVID-19, se ha reportado que la mayoría de los pacientes hacen la seroconversión entre el día 7 y 11 después de la exposición al virus, aunque algunos pacientes desarrollan anticuerpos a partir del día 3 post-infección; ; ${ }^{1,47}$ no obstante, algunos estudios indican que estos anticuerpos se detectan a partir del dia 5 después de la aparición de los síntomas; por lo que puede no ser útil la implementación de estas pruebas en el contexto de una infección aguda. Sin embargo, la detección de anticuerpos puede facilitar: i) el rastreo de contactos; ii) la vigilancia serológica; iii) la identificación de pacientes que sufrieron la enfermedad y que pueden ser inmunes; y iv) la detección de pacientes con RT-PCR negativa en fase de convalescencia.

Actualmente, varias casas comerciales ofrecen pruebas rápidas para la detección de anticuerpos $\operatorname{IgM}$ e IgG en formatos fáciles de usar como las tirillas (sticks) o inmunoensayos de flujo lateral (lateral flow), también conocidas como ensayos de inmunocromatografia que pueden realizarse en menos de $30 \mathrm{~min}$. Las casas comerciales reportan altos porcentajes de 
sensibilidad y especificidad; sin embargo, todavía es necesario realizar estudios de campo que permitan estimar parámetros en nuestra población. De acuerdo a lo anteriormente expuesto, con relación a la implementación y uso de pruebas rápidas basadas en la detección anticuerpos para la enfermedad COVID-19 y teniendo en cuenta el contexto colombiano y el consenso colombiano de atención, diagnóstico y manejo de la infección por SARS-Cov-2/COVID-19, ${ }^{8}$ me permito hacer los siguientes comentarios:

1. Estas pruebas no son confirmatorias, son pruebas de tamizaje. En todo caso, en pacientes sintomáticos con sospecha de COVID-19 y prueba rápida positiva o negativa, se debe implementar la prueba de oro o RT-PCR (Tabla 1).

2. Es recomendable su uso para evaluar la exposición a SARS-CoV-2 en pacientes a quienes se les haya realizado una prueba de RT-PCR con un resultado negativo (Tabla 1).

3. Es recomendable su uso en ciudades intermedias y municipios alejados de las ciudades donde no existe oportunidad de acceder a una prueba molecular.

4. Ante un eventual desabastecimiento de suministro o disponibilidad de reactivos para las pruebas moleculares (RT-PCR), incluyendo las pruebas comerciales aprobadas por la FDA, o por las demoras en la instalación de equipos y el suministro de reactivos/kits para satisfacer la demanda en muchos sitios, el uso de pruebas rápidas es una opción que podría ayudar a evaluar el estado de exposición del paciente.

5. Podrían ser utilizadas para hacer seguimiento de la exposición a SARS-CoV-2 en el personal de salud, dado que estarían en permanente contacto con pacientes infectados.

6. Pueden ser utilizadas en las visitas domiciliarias hechas por el personal de salud a los casos probables (point-of-care) para conocer su exposición a SARS-CoV-2 por su facilidad en el procedimiento, pero siempre teniendo en cuenta el tiempo de exposición.

7. Pueden ser utilizadas para el rastreo de contactos y estudios epidemiológicos.

8. Todo resultado debe estar acompañado de la interpretación (Tabla 1), puesto que muchos médicos se pueden confundir.
Tabla 1. Interpretación de las pruebas para detección de anticuerpos en COVID-19

\begin{tabular}{|c|l|}
\hline Resultado & \multicolumn{1}{|c}{ Interpretación } \\
\hline IgM (+) IgG(-) & $\begin{array}{l}\text { Infección reciente, se sugiere confirmar con RT- } \\
\text { PCR para COVID-19 }\end{array}$ \\
\hline IgM (+) IgG (+) & $\begin{array}{l}\text { Infección activa por SARS-CoV-2, se sugiere } \\
\text { confirmar con RT-PCR para COVID-19 }\end{array}$ \\
\hline IgM (-) IgG (+) & Infección por SARS-CoV-2 resuelta \\
\hline IgM (-) IgG (-) & No expuesto a SARS-CoV-2
\end{tabular}

Fe de erratas: https://revistas.udea.edu.co/index.php/hm/article/ view/341966

\section{Referencias}

1. Patel R, Babady E, Theel ES, Storch GA, Pinsky BA, George KS, et al. Report from the American Society for Microbiology COVID-19 International Summit, 23 March 2020: Value of diagnostic testing for SARS-CoV2/COVID-19. mBio 2020;11:e00722-20.

2. Winichakoon $P$, Chaiwarith $R$, Liwsrisakun $C$, Salee $\mathrm{P}$, Goonna A, Limsukon A, et al. Negative nasopharyngeal and oropharyngeal swab does not rule out COVID-19. J Clin Microbiol. 2020; doi. org/10.1128/JCM.00297-20.

3. Wang W, Xu Y, Gao R, Lu R, Han K, Wu G, et al. Detection of SARS-CoV-2 in different types of clinical specimens. JAMA. 2020; doi.org/10.1001/jama.2020.3786

4. Li Z, Yi Y, Luo X, Xiong N, Liu Y, Li S, et al. Development and Clinical Application of A Rapid IgM-IgG Combined Antibody Test for SARS-CoV-2 Infection Diagnosis. J Med Virol. 2020. doi: 10.1002/jmv.25727

5. Chen Y \& Li L. Comment SARS-CoV-2: virus dynamics and host response. Lancet Infect Dis. 2020. doi. org/10.1016/S1473-3099(20)30235-8.

6. Zhao AJ, Yuan Q, Wang H, Liu W, Liao X, Su Y, et al. Antibody responses to SARS-CoV- 2 in patients of novel coronavirus disease 2019. Clin Infect Dis. 2020; doi.org /10.1101/2020.03.02.20030189.

7. Guo L, Ren L, Yang S, Xiao M, Chang D, Yang F, et al. Profiling early humoral response to diagnose novel coronavirus disease (COVID-19). Clin Infect Dis. 2020. doi: 10.1093/cid/ciaa310.

8. Grupo Consenso COVID-19. Consenso colombiano de atención, diagnóstico y manejo de la infección por SARS-COV-2/COVID-19 en establecimientos de atención de la salud. Recomendaciones basadas en consenso de expertos e informadas en la evidencia. Infectio. 2020;24:3-S1. 